\title{
ROLAND BARTHES E A AULA COMO FANTASIA IDIORRÍTMICA: Proposições para um viver-junto
}

Cistiano Bedin Costa ${ }^{(*)}$

Em 1976, a assembleia de professores do Collège de France, atendendo proposta de Michel Foucault, elege Roland Barthes para a cátedra de Semiologia Literária, criada especialmente para ele. A aula inaugural, proferida em 7 de janeiro de 1977, iniciará com o questionamento acerca das razões que teriam inclinado um lugar de tamanho prestígio a receber "um sujeito incerto, no qual cada atributo é, de certo modo, imediatamente combatido pelo seu contrário" (BARTHES, 2007, p.7). Pensador sem títulos universitários, Barthes irá lecionar na instituição até 25 de fevereiro de 1980, dia em que será atropelado em frente ao mesmo Collège, no cruzamento das ruas SaintJacques e des Écoles. Um mês depois, em 26 de março, a morte o encontrará no hospital da Salpêtrière, em um quarto branco, "tão claro a ponto de quase cegar" (MARTY, 2009, p.116).

Os três anos de trabalho no Collège compreendem um período apresentado na aula inaugural como a idade do desaprender, de "deixar trabalhar o remanejamento imprevisível que o esquecimento impõe à sedimentação dos saberes, das culturas, das crenças que atravessamos", experiência que Barthes (2007, p.45), do ponto de vista didático, denomina "Sapientia", ou seja: “nenhum poder, um pouco de saber, um pouco de sabedoria, e o máximo de sabor possível”.

Os cursos e seminários ${ }^{1}$ ministrados nesses anos colocam em prática as principais propostas apresentadas na aula inaugural, na qual Barthes apresentara as linhas gerais do ensino que ali iria ministrar. Como refere Leyla Perrone-Moisés (2012, p.162-170), trata-se de um esforço de constituição de "um ensino não opressivo", da "desconstrução de toda metalinguagem", da "renúncia a um enciclopedismo tornado impossível num tempo de excesso de informações”, da "recusa do dogmatismo e, portanto, da própria fala magistral" e, sobretudo, do que se pode

\footnotetext{
${ }^{(*)}$ Professor adjunto no Departamento de Ensino e Currículo (DEC) da Faculdade de Educação (FACED) da Universidade Federal do Rio Grande do Sul (UFRGS). área de Didática, Currículo e Formação de Professores. Doutor em Educação pela UFRGS. Psicólogo pela Universidade Federal de Santa Maria (UFSM). Atuou na Universidade do Vale do Taquari (Univates) entre 2012-2016, desempenhando diversas atividades nos níveis de ensino, pesquisa e extensão. É membro dos Grupos de Pesquisa Currículo, Espaço, Movimento (CEM)(Univates), DIF - Artistagens, Fabulações, Variações (UFRGS) e Escrileituras da Diferença em Filosofia-Educação (UFRGS). Interessa-se pelas relações entre Arte, Literatura e Filosofia, tomadas como intercessores do pensamento em Educação. Com Foucault, Deleuze e Barthes, pesquisa estratégias de criação em meio às formações curriculares contemporâneas. E-mail: cristianobedindacosta@hotmail.com

${ }^{1}$ Reunidos na coleção "Os cursos e os seminários no Collège de France de Roland Barthes”, dirigida por Éric Marty, e no Brasil publicada pela editora Martins Fontes.
} 
denominar moralidade da forma: "uma ética centrada não sobre a conduta em si, individual ou coletiva, mas sobre a linguagem na qual se fundamenta e na qual se efetiva toda conduta humana".

De fato, ao contrário de tantos outros intelectuais de sua época, Barthes nunca foi considerado um militante. No entanto, a questão do poder não deixou de estar presente em sua obra, sendo retomada muitas vezes na aula inaugural e nos cursos que a seguiram. Em entrevista publicada um mês após sua morte, ele marca a linguagem como o seu "próprio limite", defendendo a ideia de que o intelectual "não pode atacar diretamente os poderes estabelecidos, mas pode injetar estilos de discursos novos para fazer com que as coisas se mexam". Nesse sentido, a escrita, a docência e a pesquisa compartilham essa espécie de compromisso contestador-estilístico, sendo a retirada (por meio de formas de expressão e condutas clandestinas, não dogmáticas) uma estratégia intolerável a qualquer forma de poder: "Pode-se enfrentar um poder pelo ataque ou pela defesa; mas a retirada é o que há de menos assimilável numa sociedade” (BARTHES, 2004a, p.504-511).

Em Roland Barthes por Roland Barthes, essa tática de errância intelectual é citada como uma verdadeira doutrina interior, denominada "atopia (do habitáculo em deriva)" (BARTHES, 2003a, p.62). Neste ensaio, interessa-nos pensar o quanto esse contínuo abandono da própria condição está intimamente ligado ao ideal de uma prática docente que tem como um de seus propósitos centrais neutralizar o poder alojado no próprio discurso magistral, sendo então necessário situá-lo não na perspectiva da lei, mas sim do desejo: “o mestre sendo um desejante, não um guru" (PERRONE-MOISÉS, 2012, p.166), e que assim abdica - naturalmente - de exercer qualquer domínio sobre um tema ou sobre seus ouvintes ${ }^{2}$.

Com Barthes, o que está em jogo é a construção de um modo de lidar com o saber, ou seja, um estilo de vida docente, uma vez que "o que pode ser opressivo num ensino não é finalmente o saber ou a cultura que ele veicula, são as formas discursivas através das quais ele é proposto" (BARTHES, 2007, p.41). De que modo, pois, "manter" um discurso sem o impor? De que modo fazer da aula um espaço de criação, propício para a "produção das diferenças" (BARTHES, 2004b,

\footnotetext{
${ }^{2}$ Ao diferenciar a atopia da utopia, Barthes (2003a, p.62) atenta para a necessária relação de dependência da utopia à ordem do sentido já instaurada, uma vez que seu movimento pode ser entendido como um partir deste espaço-tempo para um outro (desejado, fantasiado). Desse modo, uma ordem atual é aquilo do que ela procede, e é em relação a essa ordem que ela pode constituir sua singularidade, diferenciando-se de modo relativo. Por sua vez, a atopia independe de qualquer dado de realidade, já que esta é usada apenas como possibilidade de deslocamento. De certo modo, a atopia configura uma espécie de curto-circuito utópico, ou melhor, trata-se da utopia em seu devir errante, pelo qual já não visa chegar a lugar e tempo alguns, mas apenas deslizar. Se a fantasia depende da utopia, tal como é defendido por este ensaio, é porque em Barthes, ambas são parte de um processo comum de criação: fantasio uma produção (alucino a obra, a aula, a pesquisa), em detrimento de todas os dados atuais e as amarras do aqui e do agora.
} 
p.414): o trabalho continuado, incansável, de quebra da reprodução de papéis e de repetição de discursos, com as relações tendo que, pouco a pouco, voltar a se originalizar?

$\mathrm{Na}$ esteira de tais questionamentos, e tomando como guia indicações recolhidas no interior do universo barthesiano, o espaço da aula é aqui defendido como um tipo especial de Viver-Junto, dentro do qual "a coabitação não exclui a liberdade individual” (BARTHES, 2003b, p. 329), ou seja, uma vida em comum na qual o ritmo pessoal de cada um encontra o seu lugar. É a esse imaginário, denominado "fantasia ${ }^{3}$ de idiorritmia", que nos voltamos para pensar as relações de ensino e aprendizagem, não importando se o que ele formula é, literalmente, impossível: o sistema idiorrítmico pode muito bem funcionar como uma garantia de produção, desde que seus elementos retornem para o nosso mundo na forma de "clarões de desejo, possíveis excitantes" (BARTHES, 2004c, p.291). Se pudermos captá-los, estar atentos a seus mínimos sinais, talvez possamos também impedir que nossas práticas se imobilizem em sistemas totalitários, burocráticos, moralizadores ${ }^{4}$.

Questão ética, mas também política. O que vem a seguir, afinal, depende da ideia de que há uma relação fundamental entre esses dois domínios, sendo a aula um bloco de espaço-tempo privilegiado para a criação e exploração de zonas de fricção ${ }^{5}$. Vejamos, pois, algumas proposições em cujo cruzamento se encontra, a nossos olhos, uma fantasia idiorrítmica de aula: dizem respeito ao antes, ao durante, ao depois (aqui entendido como o instante do testemunho).

\footnotetext{
${ }^{3}$ Termo deslocado por Barthes do vocabulário psicanalítico, também é traduzido em algumas edições brasileiras como fantasma. Seja como for, trata-se da indicação de uma imagem cuja origem é inconsciente (e que independe, portanto, da vontade do sujeito). $\mathrm{O}$ adjetivo fantasmático é utilizado em todas as edições.

${ }^{4}$ No resumo do curso Como viver junto: simulações romanescas de alguns espaços cotidianos, escrito por Barthes (2003b, p. 329-331) para o anuário do Collège de France, a fantasia de idiorritmia não deixa de ser associada à imagem de uma realidade irrealizável. Por sua vez, o curso, pela necessária problematização de uma "distância crítica" imaginada para as relações fantasiadas, acaba fatalmente por desembocar "num problema de ética da vida pessoal".

${ }^{5}$ Tal crença também funciona como argumento central da pesquisa Atlas do corpo e do pensamento nas licenciaturas: espantos, traduções, heterotopias, desenvolvida desde novembro de 2016 junto ao Departamento de ensino e currículo da Faculdade de Educação da Universidade Federal do Rio Grande do Sul (UFRGS), sobretudo a partir do trabalho com alunos e alunas de diferentes licenciaturas da instituição. Em consonância com as metas estabelecidas no Plano Nacional de Educação, em especial no que tange às Diretrizes Curriculares Nacionais para a Formação de Professores, a pesquisa se volta para o licenciando e a licencianda no sentido de atribuir-lhes protagonismo no processo da sua formação. Com o aporte teórico do pensamento da diferença, estuda as noções de corpo, espaço e pensamento a partir de conceito propostos por Michel Foucault, Roland Barthes e Gilles Deleuze, entre outras referências filosóficas, artísticas, literárias e educacionais. Por meio de procedimentos de tradução cartográfica, propõe a constituição de um atlas multimídia, composto a partir do estudo de textos didáticos. Tais traduções, pensadas ao mesmo tempo como meio e fim dos processos de ensino e de aprendizagem, tornam-se passíveis de serem tomadas como medida, testemunho e disparador de novas estratégias pedagógicas, reconfigurando assim os espaços da aula, do currículo e da vida. O presente ensaio é parte de seus movimentos exploratórios.
} 


\section{ANTES}

\section{O guia iniciático, o fantasma}

Por onde começar? Para Barthes, na origem de um ensino - assim como na origem de uma pesquisa -, uma fantasia deve sempre ser colocada como guia iniciático (sem o qual a realização da tarefa estará fatalmente apartada do prazer). Trata-se de uma fábula interior, de uma imagem de origem inconsciente, "um romancinho de bolso que a gente leva sempre consigo e que se pode abrir em qualquer lugar" (BARTHES, 2003a, p.101). Diferente do sonho, cuja monológica nos absorve inteiramente, a fantasia permanece concomitante à consciência da realidade, delimitando um espaço duplo, escalonado, no interior do qual algo se esboça, uma voz inominada se ouve, e é, mesmo sem nenhum aparato material, um começo de produção (uma aula: de que modo precisar o seu início?).

O que a fantasia garante, portanto, é "uma volta de desejos, de imagens, que rondam, que se buscam em nós, por vezes durante uma vida toda" (BARTHES, 2003b, p. 12). Ao considerar tal imaginário, o ensino fantasmático assegura ao professor a presença de seu afeto (desejo, logo postulo, ou seja: alucino): “a primeira força que posso interrogar, interpelar, aquela que conheço em mim, embora através do logro do imaginário: a força do desejo, ou para ser mais preciso (já que se trata de uma pesquisa): a figura da fantasia" (BARTHES, 2003b, p.8).

Enquanto engendramento de forças, sobretudo pela delimitação de diferenças em relação (o desejo como garantia e medida de singularidade de cada sujeito), a fantasia funciona como uma espécie de arcabouço cultural. Ao mesmo tempo, voltar-se para o próprio desejo permite ao professor deslocar-se (mesmo que apenas um pouco) da posição a ele reservada:

"É a um fantasma, dito ou não dito, que o professor deve voltar anualmente, no momento de decidir sobre o futuro de sua viagem; desse modo, ele se desvia do lugar em que o esperam, que é o lugar do Pai, sempre morto, como se sabe; pois só o filho tem fantasmas, só o filho está vivo" (BARTHES, 2007, p. 43).

Não se trata, tal como assinalado por Éric Marty (2009, p.205), de egotismo, confissão, exibicionismo ou mesmo hedonismo estéril, mas sim da figura do mestre capaz de desconstruir imagens (sobretudo de si), "que se desprende da memória em nome da força da vida viva”. Que a força vital o lance para caminhos insuspeitos ou até mesmo disparatados, eis aí algo que sem dúvida deve ser considerado. No entanto, uma vez aceito como a indicação de uma força desejante, nenhum imaginário, por mais infactível que pareça, necessita ser sufocado em detrimento de um projeto supostamente mais concreto, real ou mesmo necessário.

Para Barthes (2004c, p.290-291), enquanto a utopia funciona como testemunho de um campo de desejo, o Político configura o campo da necessidade, "donde as relações paradoxais 
desses dois discursos: eles se completam, mas não se compreendem". Enquanto "a Necessidade acusa o desejo de irresponsabilidade, de futilidade; o Desejo acusa a Necessidade por suas censuras, seu poder redutor”. Diante disso, “o desejo precisa o tempo todo ser reconduzido ao Político”, o que significa dizer não só que as utopias são justificadas, como também são necessárias, uma vez que em aula, em pesquisa - "não são as grandes linhas de uma sociedade futura que temos que desenhar - isto está no próprio Político; são os detalhes dessa sociedade, e é nisso que nos falta utopia, desejo". A utopia - eis aí sua característica - é minuciosa, clinicamente afiada em seus esboços, nas suas prospecções ${ }^{6}$.

Está no imaginário, portanto (daquele que planeja e ensina, claro; mas não só, veremos), parte essencial do arcabouço material da aula. Explorá-lo, nesse sentido, é criar cintilações, toques, cacos de desejo. Real problema didático.

\section{O DURANTE}

\section{O lugar do corpo}

A propósito da necessidade de considerar o corpo no espaço do ensino, Barthes (2004b, p.416) provocava: "reponham o corpo no lugar de onde foi expulso e se adivinha todo um deslizamento de civilização". Para Barthes, nada é mais transgressivo do que o empenho na leitura da expressão corporal em determinado espaço, uma vez que o corpo, existência inimitável, é sempre um tanto impossível - "meu corpo não tem as mesmas ideias que eu”, dirá Barthes (2006, p.24) em outra ocasião.

Repor o corpo no lugar de onde foi expulso, deixá-lo seguir suas próprias ideias, é um modo de conferir àquele que o vive certa singularidade. É justamente por isso que, na obra barthesiana, o corpo é muitas vezes o ponto de partida, tal como se pode perceber no princípio heurístico que conduz a investigação de A câmara clara, seu último livro: "o que meu corpo sabe da fotografia?" (BARTHES, 1984, p.20). O corpo, não o eu. A carne, não a razão. A natureza, não a cultura.

As oposições binárias não são neutras, indicam a afirmação de um ethos comum, mesmo que (em certo aspecto) infeliz: antes de qualquer coisa, o corpo é aquilo que não se compartilha, não se iguala, não encontra correspondências. Em última análise, um corpo, aconteça o que acontecer, esteja onde estiver, não será igual a outro.

\footnotetext{
${ }^{6}$ Em Barthes (2004c), a impotência para escrever utopias é até mesmo proposta como um índice de platitude de determinado tempo histórico.
} 
Em Roland Barthes por Roland Barthes, esse corpo múltiplo participa de um inventário que poderia ser prolongado, quase sem limite:

Tenho um corpo digestivo, tenho um corpo nauseante, um terceiro cefalálgico, e assim por diante: sensual, muscular (a mão do escritor), humoral, e sobretudo: emotivo: que fica emocionado, agitado, entregue ou exaltado, ou atemorizado, sem que nada transpareça. (BARTHES, 2003a, p.74).

A profusão indica, a um só tempo, o corpo orgânico - detentor de peso, volume e profundidade; corpo que ocupa um lugar - e o corpo inteligente, fruto de outro corte; um corpo que age e sofre por conta própria. Se em um sentido tópico tal dimensão corporal indica um isolamento - ter um corpo, testemunhar por ele, é sempre habitar uma solidão, visto que é em oposição ao todo, ao contrato social, que um corpo se constitui -, é essa própria singularidade que evidencia a existência de outros corpos, "precisamente porque pensar, sofrer ou amar implicam um corpo rodeado, e não só, implicam também: um corpo que rodeia” (TAVARES, 2013, p.189).

Está nessa possibilidade de definição do corpo como algo que rodeia e é rodeado a correlata possibilidade de tomá-lo, a despeito de sua condição múltipla, enquanto um corpo espacial, que é influenciado pelo espaço e nele intervém.

\section{O viver junto}

Além de um campo problemático a ser explorado, a preparação da aula envolve também o cuidado com o Viver-Junto do qual ela é cenário: a aula como uma pequena comunidade móvel, na qual cada um dos membros pode "viver ao mesmo tempo em companhia e em liberdade" (PERRONE-MOISÉS, 2012, p.160). Em Ao seminário, texto dedicado à sua prática docente na École Pratique des Hautes Etudes, Barthes (2004b, p.413-414) defende ser necessário “que à geometria grosseira dos grandes cursos públicos suceda uma topologia sutil das relações corporais, de que o saber seria pré-texto". Nesse sentido, o seminário deveria se basear "muito pouco numa comunidade de ciência, antes sim numa cumplicidade de linguagem, isto é, de desejo".

O Falanstério, agrupamento utópico idealizado por Charles Fourier, no qual o viver em sociedade não esmaga o ritmo e os desejos de cada sujeito, aparece como uma referência a uma forma fantasmática do Viver-Junto. Opondo o espaço falansteriano a seu contrário, que denominará espaço edipiano (espaço repressivo, de exames, interdições e estabelecimento vertical do sentido recomendável), Barthes (2004b, p.413) reserva a si próprio o papel de "liberar a cena onde vão estabelecer-se transferências horizontais", uma vez que o que importa (o lugar do sucesso do seminário) "não é a relação dos ouvintes com o diretor, mas sim a relação dos ouvintes entre si". Em certo sentido, tem-se aí um zelo e uma atenção comuns funcionando como ethos articulador das 
relações. Nesse cenário, o professor não é nenhum sujeito sagrado, "mas apenas um regente, um operador de sessão, um regulador: aquele que dá regras, protocolos, não leis”.

\section{A benevolência, a fala pacífica}

Uma vez que "há uma relação fundamental entre o ensino e a fala", e que "toda fala está do lado da lei" (BARTHES, 2004b, p.386), o professor, que está do lado da fala, deve ao menos lutar para que no espaço de fala pelo qual ele é responsável não figure nenhuma agressividade. Trata-se de tomar a benevolência como objetivo prático: "ao escutar, ao falar, ao responder, que eu nunca seja o ator de um julgamento, de uma sujeição, de uma intimidação, o procurador de uma Causa" (BARTHES, 2004b, p.410).

Leyla Perrone-Moisés (2012, p.126), falando sobre a experiência do Viver-junto dos seminários barthesianos, faz referência a um modo especial de escuta posto em prática por Barthes, na qual a trama gestual do corpo assume o protagonismo da cena, à medida que desenvolve sua própria narrativa, seu próprio texto. Nela, os alunos "se educavam menos pelas respostas do mestre do que pelo modo como ele ouvia".

No limite, o que está em jogo é sempre uma maneira de lidar com o sentido, de táticas de recuo e abandono a partir dos quais um algo mais, não previsto, possa ter lugar. De certo modo, buscar o que Barthes denomina "fala pacífica": uma relação desarmada com palavras, ideias e gestos, uma trama capaz de arquitetar uma espécie de suspense:

Nos limites mesmo do espaço docente, tal qual é dado, tratar-se-ia de trabalhar para traçar pacientemente uma forma pura, a da flutuação [...] essa flutuação nada destruiria; contentar-seia com desorientar a Lei: as necessidades de promoção, as obrigações do ofício [...], os imperativos do saber, o prestígio do método, a crítica ideológica, tudo está aí, mas a flutuar" (BARTHES, 2004b, p.411).

Este colocar em suspensão, esta arquitetura de flutuações, distancia a prática da aula de todo compromisso revelador, uma vez que a tarefa didática aí não é pensada em termos de dar a ver ou dar a falar aquilo que não tem cara e voz, tornando-o comum: ao contrário, o que está em causa é um esforço de recuo e retração, ou seja, de inexpressão do exprimível, "como se o pensamento também fosse chamado a cavar em si uma região de refluxo, inabitada e inabitável, uma zona de cegueira e de impossibilidade, de interrupção, a fim de que algo pudesse advir” (PELBART, 2007, p.65). O mesmo diz respeito ao professor: é preciso que ele se retire, enquanto sujeito, é necessário que ele, em certo sentido, perca seu rosto (o rosto no qual se pode ler as palavras da Lei), num movimento que já não representa omissão ou derrota, mas puro zelo: pacífica, a fala é também 
exata, não gregária. Pelo seu livre jogo, torna-se capaz de instaurar um espaço outro, capaz de contestar mítica e realmente os espaços onde vivemos.

\section{A excursão}

A didática barthesiana é digressiva. A aula, portanto, é uma excursão, com a fala e a escuta "semelhantes às idas e vindas de uma criança que brinca em torno da mãe, dela se afasta e depois volta, para trazer-lhe uma pedrinha, um fiozinho de lã, desenhando assim ao redor de um centro calmo toda uma área de jogo, no interior do qual a pedrinha ou a lã importam finalmente menos do que o dom cheio de zelo que deles se faz" (BARTHES, 2007, p.43).

Enquanto movimentos do desejo, arrepios do corpo, as idas e vindas ao redor do tema (segurança fantasmática) não permitem a instauração de nenhum caminho reto, nenhuma evolução, nenhum final programado e capaz de oferecer um resultado concreto ao trabalho da aula, articulada então como uma espécie de aventura em meio a diferentes campos de saber. Tráfego, mas também tráfico: conceitos, sons, imagens, nuances de sentido arrastados de um lado a outro, por intermédio do corpo que sente, toca e é tocado.

De sua biblioteca interior, o professor (aquele que sonha alto sua pesquisa) retira os materiais que julga pertinentes ao tema pesquisado, arranja-os ao sabor de suas leituras e lembranças, insere-os na trama imprevisível da aula. Em diversos sentidos, trata-se de um oferecimento: ao apresentar o que me toca, ofereço a parte precisa (o naco exato) onde faço corpo com o outro, e torço (mais, não posso) para que possamos despertar algum apetite (com o cutelo em mãos, o aluno escolhe o que mais lhe apetece, desmembra o discurso, arranca e toma para si o que tiver mais sabor).

Trata-se, pois, da aventura de um corpo inteligente, e por isso intratável: "um simples plural de encantos, lugar de pormenores sutis [...] canto descontínuo de amabilidades" (CORAZZA, 2013, p.88); "corpo que se empurra e volta a empurrar, passa para outra coisa - pensa noutra coisa" (BARTHES, 2009, p.288); corpo de intermezzos, que muda de lugar, muda de postura, muda de tom, impede que o discurso se agarre, engrosse, espalhe-se e desenvolva-se. Uma vez assim concebido, o ensino está intimamente ligado à criação de novos arranjos e ao traçado de novas dimensões de pensamento e existência, não fazendo sentido considerá-lo enquanto esforço linear, natural e progressivo a uma determinada direção, mas sim como constituição de espaços, de novos eixos pelos quais o pensamento poderá se desenvolver. 


\section{A anotação louca}

Obviamente, nessa aventura, pode-se tomar notas. No entanto, o registro não visa copiar o saber como modelo, não quer aprisionar o dito e o vivido no espaço da folha, a fim de poder posteriormente representá-los. Ao contrário: a nota é o território da falha da Lei, pela autonomia da escuta ao se destacar do que é dito. Em suma, a nota é escritura, é ação de autoria, e não memória e cópia. Ela se define pela produção, e não por uma representação - tomar a escuta: ação sem dúvida mais subversiva que tomar a palavra. De acordo com Perrone-Moisés (2012, p.127), ao encorajar o que denominava "anotação louca", Barthes acreditava que, ao acolher em seu discurso apenas o que acenasse a seu desejo, o aluno teria chance de produzir um texto novo, pessoal, "e era o que ele queria receber de volta, e não a imagem especular de seu próprio discurso, por ele conhecido, e portanto tedioso".

Desse modo, ao mesmo tempo em que "alguém trabalha, pesquisa, produz, reúne, escreve diante dos outros", todos "se incitam, se chamam, põem em circulação o objeto a produzir, o processo a compor, que passam assim de mão em mão, suspensos ao fio do desejo, tal como o anel no jogo de passa anel” (BARTHES, 2004b, p.418).

\section{A tessitura dos sentidos}

"O nascimento do leitor deve pagar-se com a morte do Autor”. Com essa fórmula, Barthes (2004b, p.64) encerrava, em 1968, A morte do autor, ensaio-manifesto cujo propósito e provocação permanecem ainda atuais. Para Barthes, o afastamento do autor - personagem a partir da qual a tradição moderna acaba por estabelecer um vínculo íntimo entre os ditos produtor e produto, de modo que "a explicação da obra é sempre buscada do lado de quem a produziu" - configura-se como a abertura de um campo exploratório no qual "a pretensão de decifrar um texto torna-se totalmente inútil” (BARTHES, 2004b, p.63), uma vez que o desafio literário não se constitui pelo segredo, mas sim por uma espécie de deslindamento: em meio à obra, o leitor é aquele que deverá percorrer um espaço, dispersar seus elementos estruturais, e não penetrá-lo na busca por um sentido último e profundo. Trata-se, para Barthes, de assumir o jogo literário como uma atividade "contrateológica" e propriamente revolucionária, "pois a recusa de deter o sentido é finalmente recusar Deus e suas hipóstases, a razão, a ciência, a lei”.

Sem dúvida, tal jogo não seria possível sem um entendimento particular da noção de texto, não mais pensando como uma linha de palavras a produzir um único sentido (a transmissão de determinada mensagem), "mas um espaço de dimensões múltiplas, onde se casam e se contestam escrituras variadas, das quais nenhuma é original” (BARTHES, 2004b, p.62). Para Barthes, o texto 
não é mais que um tecido de "citações sem aspas" (BARTHES, 2004b, p.71), e escrever é sempre adentrar em uma operação já em andamento, estendendo os gestos que a constituem. O escritor, por condição retardatário, é assim aquele cujo único poder está em mesclar escrituras e citações "oriundas de mil focos da cultura", de modo que, mesmo que queira exprimir-se, deve ao menos saber que “a 'coisa' interior que tem a pretensão de 'traduzir' não é senão um dicionário todo composto, cujas palavras só se podem explicar através de outras palavras, e isto indefinidamente" (BARTHES, 2004b, p.62). Necessariamente impuro, o espaço literário exige daquele que o percorre o exercício de uma dispersão que não pode ter parada, mesmo que encontre, na figura do leitor, o espaço próprio de uma inscrição: ele é esse alguém capaz de configurar um arranjo de traços a partir dos quais é constituído o escrito.

Em O prazer do texto, a leitura será pensada como uma espécie de exercício de estrangeiridade, capaz de suportar "sem nenhuma vergonha" a contradição lógica. Para Barthes, o leitor do texto, desde que entregue a seu prazer - "esse momento em que meu corpo vai seguir suas próprias ideias" (BARTHES, 2006, p.24) -, é ficcionalizado como um indivíduo capaz de misturar todas as linguagens, ainda que sejam consideradas incompatíveis; que suporta todas as acusações de ilogismo, de infidelidade, e sobretudo a não-unidade de si. Voltar-se para essa figura, percorrer as linhas de sua leitura, é buscar não uma identidade, mas sim o que o separa dos demais, o dado que demarca a sua singularidade. Se o interesse de Barthes deixa de estar voltado para a consideração do texto como objeto intelectual (de reflexão, de análise, de comparação), é porque, ao realizar-se a pleno, o prazer do texto é justamente isso que faz com que o livro transmigre para dentro da vida daquele que o percorre, e a escritura do outro escreva fragmentos de nossa própria cotidianidade (BARTHES, 1979, p.10).

A distinção estabelecida entre as noções de texto obra configura-se como eixo central para tais proposições. Enquanto a última é computável, segura-se na mão e encerra-se sobre o significado (ela é aquilo que se mostra e que é visto, enumerado e catalogado conforme a sua verdade, sua filiação e seu sentido), o texto "aborda-se, prova-se com relação ao signo" (BARTHES, 2004b, p.68): enquanto a obra depende da interpretação, o texto não pode ser provado a não ser em uma produção, demonstra-se na travessia que ao mesmo tempo o estende e o constitui. É nesse sentido que, com Barthes, entendemos o texto como uma tessitura não apenas gramatical, mas também subjetiva: no jogo com o signo literário, ele é isso que escorre e que resiste à imposição do sentido, um a mais irredutível aos desígnios do sujeito e da obra, mas que não cessa de os constituir em seus interstícios. 
Texto quer dizer Tecido; mas, enquanto até aqui esse tecido foi sempre tomado por um produto, por um véu todo acabado, por trás do qual se mantém, mais ou menos oculto, o sentido (a verdade), nós acentuamos agora, no tecido, a ideia gerativa de que o texto se faz, se trabalha através de um entrelaçamento perpétuo; perdido neste tecido - nessa textura - o sujeito se desfaz nele, qual uma aranha que se dissolvesse ela mesma nas secreções construtivas de sua teia. (BARTHES, 2006, p.74-75).

A perspectiva hifológica da análise barthesiana estabelece, tanto para a obra quanto para aquele que a encontra, um corte diferente daquele pelo qual a intencionalidade, o significado e sua interpretação estabelecem as condições gerais para a experiência literária. Esforço semelhante é empregado na análise de outras poéticas criadoras, tal como a fotografia, o cinema, a música e a pintura, configurando aquilo que Italo Calvino, em um bonito ensaio escrito na ocasião da morte de Barthes, entende ser um incansável esforço de coação da "impessoalidade do mecanismo linguístico e cognitivo" a fim de que a "fisicidade do sujeito vivente e mortal" possa ser considerada (CALVINO, 2010, p.84). É justamente nessa tensão, "nesse debate no fim das contas convencional entre a subjetividade e a ciência", tal como escreve Barthes (1984, p.19) em A câmara clara, que podemos encontrar a indicação de uma ética possível: a resistência a qualquer sistema redutor e o compromisso com o singular e o irrepetível, estando a generalização científica e a sensibilidade poética, portanto, necessariamente enlaçadas.

$\mathrm{Na}$ esteira de tal compromisso, interessa pensar a aventura da aula em relação às possibilidades de criação de novos sentidos, entendendo o espaço nela constituído como efetivamente um espaço textual, ou seja, um espaço cuja prática a ele vinculada seja capaz de inscrever a significância: um regime de sentido jamais fechado sobre um significado único, dentro do qual o sujeito, "quando escuta, fala, escreve, e mesmo no nível de seu texto interior, vai sempre de significante em significante, através do sentido, sem jamais fechá-lo" (BARTHES, 2004c, p.297). Uma textualidade, portanto, efetiva-se por uma prática significante, determinada maneira de estar juntos (com as obras, com os saberes, com o outro) onde o movimento do sentido não é mais que a simples sugestão de um disparo, uma centelha capaz de acender o desejo criador.

Nesse sentido, pode-se dizer que o trabalho didático é também portador de um convite, cujo aceite implica necessariamente lançar-se em uma aventura de construção de novas paisagens existenciais, ou seja, novas formas para a vida. No entanto, nada disso se faz possível sem uma verdadeira desmistificação do espaço da aula, de modo que a distância entre os seus participantes e o saber a ela vinculado seja medida apenas pela qualidade do encontro que os une. Tal como sugere Pellejero (2012, p.66), "relacionar aquilo que vemos, ouvimos, lemos ou tocamos com a nossa própria experiência continua estando na medida daquilo que talvez fosse possível chamar de utopia 
estética", caracterizada sobretudo pelo desaparecimento dos limites que acabam por impossibilitar a aproximação entre os desejos do autor e daquele que os encontra ${ }^{7}$. É só assim, pela criação dessa zona neutra de ressonâncias e de contágios, que a aula pode se configurar como sendo algo mais que uma voz monofônica, presa e dependente de um único sentido: suficientemente próximos, os saberes se tornam capazes de dar a fazer, e não apenas dar a ver, a ouvir, a tocar ou a sentir.

\section{O DEPOIS}

\section{A contemporaneidade, o testemunho}

Pelo texto - espaço estereográfico, que percorro através do trabalho com o plural dos sentidos, pelo jogo móvel dos significantes, pela recusa e deriva do sentido único -, pode-se liberar o Viver-Junto dos limites estritos de uma relação espaço-temporal. Textual, ele diz respeito a uma contemporaneidade, aqui tomada em seu sentido pleno: somos (ou ao menos podemos ser) contemporâneos da força de um pensamento, de maneira que o calendário e a geometria não respondem bem à pergunta sobre o viver com:

Viver com um autor não significa necessariamente cumprir em nossa vida o programa traçado nos livros desse autor [...] não se trata de operar o que foi representado, não se trata de tornarse sádico com Sade, falansteriano com Fourier, orante com Loyola; trata-se de fazer passar na nossa cotidianidade fragmentos de inteligível (fórmulas) provindos do texto admirado (admirado justamente porque se difunde bem); trata-se de fazer falar esse texto, não de o agir, deixando-lhe à distância de uma citação, a força de irrupção de uma 7palavra bem cunhada, de uma verdade de linguagem; nossa vida cotidiana se torna então ela própria um teatro que tem como cenário nosso próprio hábitat social. (BARTHES, 1979, p.7).

Faz-se necessário, para "fazer falar" aqueles com quem vivo junto, que esse espaço de produção constituinte do texto não seja interrompido, uma vez que o tornar-se contemporâneo é precisamente a demarcação de uma zona de encontro, dentro da qual a aula pode se constituir como um campo de experimentação de determinado modo de pensar, e não sua mera transmissão.

\footnotetext{
${ }^{7}$ Condição necessariamente construtivista do desejo em Barthes: desejar é tender $a$, ou seja, colocar-se em intensão: de encontrar, de criar, de compor. Desejar é estar aberto ao fazer. Nesse sentido, não apenas desejamos, mas também somos desejados: por autores, por pensamentos, por obras, tal como indicado em O prazer do texto: "O texto que o senhor escreve tem de me dar prova de que ele me deseja. Essa prova existe: é a escritura" (BARTHES, 2006, p.11). Pelo desejo, o prazer de ler torna-se prática de escrita, ou seja, testemunha-se uma mudança de intensidade, o contágio, a proliferação. Dar a ler: dar a escrever. No que diz respeito à aula, parece-nos que esse desejo não pode ser outro que não o próprio exercício do pensamento e da correlata construção de novos sentidos. Uma vez desejados pela aula, somos convocados não propriamente a entende-la, mas sim a multiplica-la, proliferando seus signos por outras aulas, outras textualidades, por outras maneiras.
} 
Por essa perspectiva, o que se pode aprender e, portanto, levar adiante, é um certo indício de prazer, ou seja: uma co-existência. Nela, talvez seja possível cumprir a primeira das missões delegadas por Barthes (2004b, p.361) a seus últimos cursos (e que também deveria nortear seus projetos futuros, interrompidos pela morte): “dizer aqueles que se ama”, testemunhar por eles, garantindo assim que não tenham vivido, pensado (e muitas vezes sofrido) em vão. Salvas da frieza ou mesmo do nada da história, essas existências são recolhidas, justificadas em uma produção presente.

A aula, a pesquisa, o Viver-Junto, tornam-se então pinturas, dramatizações de vidas distantes, textualmente aproximadas. Para tanto, o professor não diz o que sente; não fala, egoisticamente, a respeito de seu sentimento sobre nada e nem ninguém; ao contrário, ele comunica (se preferirmos: difunde, irradia), encarna, torna possível o toque, a degustação.

\section{Sapientia, enfim, o máximo de sabor possível}

É pelo texto, portanto, pela dispersão da qual ele é constituído e pela qual se movimenta, que a fantasia do Viver-Junto encontra aquela que podemos considerar sua forma plena: nela, mestre e aprendiz estão comprometidos com uma mesma ordem afetiva, pois sabem que é só por sua produção (esse esforço amoroso que dá continuidade ao jogo), que isso que os toca pode durar um pouco mais. 


\section{REFERÊNCIAS}

BARTHES, R. Sade, Fourier, Loyola. Lisboa: Edições 70, 1979.

A Câmara clara. Rio de Janeiro: Nova Fronteira, 1984.

Roland Barthes por Roland Barthes. São Paulo: Estação Liberdade, 2003a.

Como viver junto: simulações romanescas de alguns espaços cotidianos. São Paulo: Martins Fontes, 2003 b. O grão da voz. São Paulo: Martins Fontes, 2004a.

O rumor da língua. São Paulo: Martins Fontes, 2004b.

Inéditos, I: teoria. São Paulo: Martins Fontes, 2004c.

O prazer do texto. São Paulo: Perspectiva, 2006.

Aula. São Paulo: Cultrix, 2007.

O obvio e o obtuso. Lisboa: Edições 70, 2009.

CALVINO, I. Coleção de areia. São Paulo: Companhia das Letras, 2010.

CORAZZA, S. M. O que se transcria em educação? Porto Alegre: UFRGS, 2013.

MARTY, É. Roland Barthes, o ofício de escrever: ensaio. Rio de Janeiro: DIFEL, 2009.

PELBART, P. P. Excurso sobre o desastre. In: QUEIROZ, A.; MORAES, F.; VELASCO E CRUZ, N. (Orgs.). Barthes/Blanchot: um encontro possível. Rio de Janeiro: 7 Letras, 2007. p. 65-74.

PERRONE-MOISÉS, L. Com Roland Barthes. São Paulo: Editora WMF Martins Fontes, 2012.

PELlEJERO, E. Modos de fazer / Modos de ver / Modos de pensar (Arte sem superstições). In: DIAS, S.O.; ANDRADE, E. C. P.; AMORIN, A. C. R. (Orgs.). MultiTão: experimentações, limites, disjunções, artes e ciências... Feira de Santana: UEFS Editora, 2002. p. 66-78.

TAVARES, G. Atlas do corpo e da imaginação. Lisboa: Editora Caminho, 2013. 


\section{RESUMO}

Toma-se a obra de Roland Barthes como matéria de investigação. Nela, a noção de Viver-junto sugere um imaginário de aula enquanto espaço idiorrítmico, uma vida em comum na qual desejo e ritmo individuais encontram seus lugares. Através de proposições sobre preparação, prática e registro da aula, lida-se com noções barthesianas tais como fantasia, corpo e texto. Nesse percurso, discute-se as posições ocupadas por professor, aluno e os modos pelos quais saber e cultura veiculados ao ensino podem construir um espaço propício à produção de diferenças, à quebra da reprodução de papéis e de discursos. Enquanto prática de idiorritmia, o ensino efetiva um modo de estar junto no qual o movimento do sentido se constitui como a simples sugestão de um disparo, uma centelha capaz de acender o desejo.

Palavras-chave: Roland Barthes. Aula. Idiorritmia. Viver-Junto.

\section{ROLAND BARTHES Y LA CLASE COMO FANTASÍA IDIORRÍTMICA: PROPOSICIONES PARA UN VIVIR-JUNTO RESÚMEN}

La obra de Roland Barthes va a ser considerada como matéria de investigación. Mientras tanto, la noción de Vivir-Junto como un imaginario de lo cual la clase puede ser pensada como un espacio idiorrítmico, una vida en común en que deseo y ritmo de cada uno encuentra sus lugares. A través de proposiciones sobre preparación, práctica y registro de la clase fantaseada, van a ser tratadas nociones tales como fantasía, cuerpo y texto. En ese recorrido se discute las posiciones ocupadas por profesor, alumno, y los modos por los cuales saber y cultura difundidos por la enseñanza pueden ser propuestos con el fin de hacer un espacio adecuado para la producción de diferencias, el romper con la reproducción de los roles y la repetición de los discursos. Como práctica de idiorritmia, la enseñanza efectiva determinada forma de estar junto en que el movimiento del sentido constituyese como la simple sugerencia de un disparo, una chispa que puede encender el deseo.

Palabras-clave: Roland Barthes. Clase. Idiorritmia. Vivir-Junto.

\section{ROLAND BARTHES AND THE LESSON AS IDIORRHYTHMIC FANTASY: PROPOSITIONS FOR LIVING TOGETHER}

ABSTRACT

Roland Barthes' work is considered as a subject of research. In this context, the notion of Living-together is chosen as imaginary from which the lecture can be thought of as an idiorrhythmic space, a life in common in which one's personal desire and rhythm finds its place. Through propositions on preparation, practice and recording of the lesson, one deals with barthesian notions such as fantasy, body and text. Along the way, we discuss the positions occupied by the professor, student and especially the ways in which knowledge and culture conveyed to teaching can be proposed in order to make the lesson a conducive space to the production of differences, of breaking the reproduction of roles and the repetition of discourses. As a practice of idiorrhythmia, the place of education offers a way of being together in which the movement of meaning is constituted as a simple suggestion of a shot, a spark capable of igniting desire.

Keywords: Roland Barthes. Lecture. Idiorrhythmia. Living together. 